\title{
Toward a 21st-Century Health Care System: Recommendations for Health Care Reform
}

Kenneth Arrow, PhD; Alan Auerbach, PhD; John Bertko, BS; Shannon Brownlee, MS; Lawrence P. Casalino, MD, PhD; Jim Cooper, JD; Francis J. Crosson, MD; Alain Enthoven, PhD; Elizabeth Falcone; Robert C. Feldman, MD; Victor R. Fuchs, PhD; Alan M. Garber, MD, PhD; Marthe R. Gold, MD, MPH; Dana Goldman, PhD; Gillian K. Hadfield, JD; Mark A. Hall, JD; Ralph I. Horwitz, MD; Michael Hooven, MS; Peter D. Jacobson, JD, MPH; Timothy Stoltzfus Jost, JD; Lawrence J. Kotlikoff, PhD; Jonathan Levin, PhD; Sharon Levine, MD; Richard Levy, PhD; Karen Linscott, MA; Harold S. Luft, PhD; Robert Mashal, MD; Daniel McFadden, PhD; David Mechanic, PhD; David Meltzer, MD, PhD; Joseph P. Newhouse, PhD; Roger G. Noll, PhD; Jan B. Pietzsch, PhD; Philip Pizzo, MD; Robert D. Reischauer, PhD; Sara Rosenbaum, JD; William Sage, MD, JD; Leonard D. Schaeffer; Edward Sheen, MD, MBA; B. Michael Silber, PhD; Jonathan Skinner, PhD; Stephen M. Shortell, PhD, MPH; Samuel O. Thier, MD; Sean Tunis, MD; Lucien Wulsin Jr., JD; Paul Yock, MD; Gabi Bin Nun, MA; Stirling Bryan, PhD; Osnat Luxenburg, MD; and Wynand P.M.M. van de Ven, PhD

The coverage, cost, and quality problems of the U.S. health care system are evident. Sustainable health care reform must go beyond financing expanded access to care to substantially changing the organization and delivery of care. The FRESH-Thinking Project (www.freshthinking.org) held a series of workshops during which physicians, health policy experts, health insurance executives, business leaders, hospital administrators, economists, and others who represent diverse perspectives came together. This group agreed that the following 8 recommendations are fundamental to successful reform:

1. Replace the current fee-for-service payment system with a payment system that encourages and rewards innovation in the efficient delivery of quality care. The new payment system should invest in the development of outcome measures to guide payment.

2. Establish a securely funded, independent agency to sponsor and evaluate research on the comparative effectiveness of drugs, devices, and other medical interventions.

3. Simplify and rationalize federal and state laws and regulations to facilitate organizational innovation, support care coordination, and streamline financial and administrative functions.

4. Develop a health information technology infrastructure with national standards of interoperability to promote data exchange.
5. Create a national health database with the participation of all payers, delivery systems, and others who own health care data. Agree on methods to make de-identified information from this database on clinical interventions, patient outcomes, and costs available to researchers.

6. Identify revenue sources, including a cap on the tax exclusion of employer-based health insurance, to subsidize health care coverage with the goal of insuring all Americans.

7. Create state or regional insurance exchanges to pool risk, so that Americans without access to employer-based or other group insurance could obtain a standard benefits package through these exchanges. Employers should also be allowed to participate in these exchanges for their employees' coverage.

8. Create a health coverage board with broad stakeholder representation to determine and periodically update the affordable standard benefit package available through state or regional insurance exchanges.
$\mathrm{T}$ he FRESH-Thinking project (www.fresh-thinking.org) convenes a multidisciplinary group of scholars who collaborate to comprehensively study the specific, detailed challenges to health care reform. This group represents diverse sectors of the health care system and beyond-physicians, health policy experts, health insurance executives, business leaders, hospital administrators, economists, and others. Through the FRESH-Thinking project, the authors met in a series of 8 workshops to delineate "essential foundations" necessary for fundamental reforms in the U.S. health care system.

Despite diverse perspectives and policy positions, the group agreed that the United States must create a health care system that provides all Americans access to an affordable, standard benefits package. We must simultaneously build the capabilities, infrastructure, and incentives to ensure that all Americans receive high-quality care. Through an iterative process of debate and comment, we found common ground on 8 fundamental policy recommendations to achieve these aims.

In formulating the recommendations, we achieved consensus on the following underlying observations and principles: First, the main problems of the U.S. health care system-coverage, cost, and quality — are well understood and well documented. Second, improving access alone is insufficient. Most discussions about reforming the system primarily focus on how to finance expanded coverage. Sustainable reform, however, must substantially change both the financing of care and the systems for organizing and delivering care. Finally, doing nothing is not an option. Maintaining the status quo in health care represents a significant threat to government finances, the economy, Americans' standard of living, and our nation's future.

See also:

Print

Editorial comment. . . . . . . . . . . . . . . . . . . . . . . 498

Related articles 485,490

Web-Only

Dialogue on health care reform 
It is impossible to solve the problem of access to health care services without fixing the financing system. But without fixing the delivery system, it is impossible to solve the cost and quality problems in a sustainable manner. Escalating costs will undermine access, and poor quality will add costs and undermine the overall value of health care coverage. Patchwork and haphazard incremental changes have not and will not create a sustainable system. Reform requires a systematic, goal-directed process; new programs and policies must offer a coordinated and coherent approach, and they must reinforce each other. For instance, a health information technology infrastructure and better outcomes measures are necessary to pay physicians and other providers on the basis of results, but merely providing the infrastructure without reasons for clinicians to use it will simply add expense.

Reform of the health system will not occur overnight. We must find a place to start. Mindful of the urgency, we have formulated these 8 recommendations as an essential foundation to achieve needed fundamental reforms regardless of the particular policy options chosen. Some of the recommendations pertain to reform of the delivery system and others to reform of the financing system.

\section{Reform of the Delivery System}

1. Replace the current fee-for-service payment system with a payment system that encourages and rewards innovation in the efficient delivery of quality care. The new payment system should invest in the development of outcome measures to guide payment.

Current payment mechanisms reward the provision of narrowly defined services and increased product volume, independent of appropriateness or health outcomes. Instead, payments should be linked to improving patient outcomes, reducing racial and other disparities in outcomes, increasing efficiency, and moderating the growth in the cost of care. Linking payment to outcomes will require continued investment in the systematic development of outcomes measures.

Current efforts are laudable, but they should be augmented with the development and rigorous evaluation of additional pilot and demonstration projects that use different payment mechanisms, such as bundled or global payments and capitation, as well as new ways of organizing and delivering care. These projects must use clear performance criteria so that the system rewards the approaches known to improve patient outcomes or save resources and terminates those that compromise patient outcomes or increase the cost of care. Because of their important role in the health care system, Medicare and Medicaid can lead the efforts in payment reform.

2. Establish a securely funded, independent agency to sponsor and evaluate research on the comparative effectiveness of drugs, devices, and other medical interventions.

Data are lacking on the effectiveness of medical interventions and processes of care. An independent agency not subject to interest-group pressures should sponsor both analyses of existing data and new research on the effectiveness, comparative effectiveness, and cost-effectiveness of health care diagnostics, therapeutics, procedures, and processes of care. All public and private payers (including selfinsured organizations) benefit from such assessments and should contribute resources to funding the agency. The data, analytic methods, and evaluative criteria used should be transparent and the results of its research widely disseminated to the public, physicians, government agencies, insurers, and other health care providers to inform health decisions.

3. Simplify and rationalize federal and state laws and regulations to facilitate organizational innovation, support care coordination, and streamline financial and administrative functions.

Both federal and state laws and regulations provide inconsistent requirements that frequently inhibit reform of the health care system, especially the coordination of care among various providers and more effective use of physicians, nurses, and other providers. Reform should include, but not be limited to, state laws and regulations governing the corporate practice of medicine doctrine and scope of practice limitations. The states should retain authority for enforcement of provider licensure, credentialing, and consumer protections. Federal and state laws should be revised to allow gain-sharing in situations with bundled or aggregated payments that improve patient outcomes, reduce disparities, or enhance efficiency.

4. Develop a health information technology infrastructure with national standards of interoperability to promote data exchange.

Effective deployment of health information technology is essential for collecting data on outcomes to guide quality improvement. A successful health information "superhighway" requires the rapid development and implementation of national standards for interoperability and exchange of electronic data to facilitate the collection and sharing of data on health care quality, outcomes, and cost throughout the health care system.

5. Create a national health database with the participation of all payers, delivery systems, and others who own health care data. Agree on methods to make de-identified information from this database on clinical interventions, patient outcomes, and costs available to researchers.

Most health plans and health care providers do not effectively use existing data to improve the efficiency and quality of care. The expansion of health information technology recommended above will provide additional sources of valuable data. To effectively use these data in improving the health care system, national standards should be implemented for combining the data to ensure consistency and comparability. Researchers using transparent and established methods should have as much access as possible, but patient confidentiality and an appropriate level of proprietary interests should be protected. 


\section{Reform of the Financing System}

6. Identify revenue sources, including a cap on the tax exclusion of employer-based health insurance, to subsidize health care coverage with the goal of insuring all Americans.

Everyone is aware of the tens of millions and growing numbers of uninsured Americans. More than $70 \%$ of these Americans lack insurance because they cannot afford it. Revenue sources, including but not limited to savings from capping the tax exclusion of employer-based health insurance, taxing tobacco, and redirecting existing health resources, should be mobilized to ensure coverage for all Americans.

7. Create state or regional insurance exchanges to pool risk, so that Americans without access to employer-based or other group insurance could obtain a standard benefits package through these exchanges. Employers should also be allowed to participate in these exchanges for their employees' coverage.

Because of risk selection and underwriting, the small group and individual insurance markets perform poorly. Exchanges in which insurance companies offer a standard benefits package with guaranteed issue, portability, and renewability and no exclusions for preexisting conditions can expand the offerings to small groups and persons at lower rates. Along with mandatory coverage for standard benefits, the exchanges must implement risk-adjusted payments to minimize adverse selection. These mandates on insurance companies must be matched by mechanisms to ensure complete participation of those eligible to prevent the accumulation of only high-risk persons within the exchange. Potential mechanisms include substantial subsidies, possibly combined with enforceable mandates. Employers should be allowed to participate in these exchanges for their employee coverage.

8. Create a health coverage board with broad stakeholder representation to determine and periodically update the affordable standard benefit package available through state or regional insurance exchanges.

For insurance exchanges to operate efficiently with competition on cost and value, they must have standard benefits packages. Design of these standard benefits packages will entail attention to many technical details and tradeoffs. An independent board with broad input would be best able to formulate options for standards benefits packages that Congress and the current administration could accept or reject. These packages could also define the base coverage that employer-based plans must meet to be eligible for tax exclusions. Individual participants should have the option to purchase packages with more coverage.

The challenge of creating consensus is significant but surmountable. The FRESH-Thinking project demonstrates that, despite diverse backgrounds and interests, people can agree on fundamental elements that will provide a solid foun- dation for a health care system. The essence of these elements is the reform and modernization of how we both finance and deliver health care to ensure real value- better quality care and improved health of Americans at sustainable growth in costs.

From Stanford University, Stanford; University of California, Berkeley, Los Angeles, and San Francisco; University of Southern California, Los Angeles; The Permanente Medical Group, Oakland; Hill Physicians Medical Group, San Ramon; Varian Medical Systems and Palo Alto Medical Foundation Research Institute, Palo Alto; and Insure the Uninsured Project, Santa Monica, California; University of Michigan, Ann Arbor, Michigan; University of Chicago, Chicago, Illinois; Humana, Louisville, Kentucky; Enable Medical Technologies, Cincinnati, Ohio; University of Texas at Austin, Austin, Texas; Wake Forest University, Winston-Salem, North Carolina; Washington and Lee University, Lexington, Virginia; New America Foundation, The Leapfrog Group, The Urban Institute, George Washington University, and the U.S. House of Representatives, Washington, DC; Center for Medical Technology Policy, Baltimore, Maryland; Rutgers University, New Brunswick, New Jersey; Weill Cornell Medical College, Ithaca, and City University of New York, New York, New York; Boston University, NKT Therapeutics, and Harvard University, Boston, Massachusetts; Dartmouth School of Medicine, Hanover, and Dartmouth Institute for Health Policy \& Clinical Practice, Lebanon, New Hampshire; Ben Gurion University, Beer Sheva, Ministry of Health, Jerusalem, Israel; University of Birmingham, Edgbaston, Birmingham, United Kingdom; and Erasmus University, Rotterdam, the Netherlands.

Disclaimer: The views presented in this work represent the views of the authors and not the views of their employers or of the U.S. government.

Acknowledgment: The authors thank Dr. Ezekiel Emanuel for his leadership in organizing the FRESH-Thinking workshops and helping to prepare initial drafts of the manuscript and Emily Tashman for her administrative support.

Potential Financial Conflicts of Interest: Employment: F.J. Crosson (Kaiser Permanente); R. Mashal (NKT Therapeutics); L. Wulsin Jr. (Director, Insure the Uninsured Project). Consultancies: J.P. Newhouse (Director, Aetna); L. Schaeffer (consultant to private equity firm). Stock ownership or options: R. Mashal (equity ownership, public and private biotechnology companies); D. Mechanic (McKesson Corporation); J.P. Newhouse (equity ownership, Aetna); L. Schaeffer (Pharmaceutical companies and outpatient surgery centers); S.O. Thier (Director, Charles River Laboratories; Director, Merck \& Co.). Grants received: D. Mechanic (Robert Wood Johnson Foundation); L. Wulsin Jr. (The California Endowment, The California Wellness Foundation, L.A. Care Health Plan, Blue Shield of California Foundation). Royalties: D. Mechanic (The Truth about Health Care: Why Reform is Not Working in America. Piscataway, NJ: Rutgers Univ Pr; 2006.) Other: J.P. Newhouse (Director of NCQA [unpaid]).

Requests for Single Reprints: Stephen M. Shortell, PhD, MPH, School of Public Health, University of California, Berkeley, 50 University Hall, Berkeley, CA 94720.

Current author addresses are available at www.annals.org. 
Current Author Addresses: Drs. Arrow, Fuchs, Levin, and Noll: Department of Economics, Stanford University, Landau Economics Building, 579 Serra Mall, Stanford, CA 94305-6072.

Dr. Auerbach: Department of Economics and School of Law, University of California, Berkeley, 549 Evans Hall \#3880, Berkeley, CA 94720 3880.

Mr. Bertko: 1084 East Sterling Lane, Flagstaff, AZ 86001.

Ms. Brownlee: New America Foundation, 1899 L Street NW, Suite 400, Washington, DC 20036.

Dr. Casalino: Department of Public Health, Weill Cornell Medical College, 402 East 67th Street, New York, NY 10021.

Mr. Cooper: U.S. Congressman, Tennessee 5th District, U.S. House of Representatives, 1536 Longworth House Office Building, Washington, DC 20515.

Dr. Crosson: Kaiser Permanente Institute for Health Policy, 1950 Franklin Street, 20th Floor, Oakland, CA 94612.

Dr. Enthoven: Graduate School of Business, Stanford University, 518 Memorial Way, Stanford, CA 94305-5015.

Ms. Falcone: U.S. Congress, 1536 Longworth House Office Building, Washington, DC 20515.

Dr. Feldman: Hill Physicians Medical Group, 868 Paramount Road, Oakland, CA 94610-2437.

Dr. Garber: Department of Veterans Affairs Palo Alto Care System and Center for Health Policy, Stanford University, 117 Encina Commons, Stanford, CA 94305-6019.

Dr. Gold: City College, City University of New York, 138th Street and Convent Avenue, Room J 920, New York, NY 10031.

Dr. Goldman: David Geffen School of Medicine and School of Public Health, University of California, Los Angeles, PO Box 951772, Los Angeles, CA 90095.

Ms. Hadfield: Law Center and Department of Economics, University of Southern California, 699 Exposition Boulelvard, Los Angeles, CA 90089-0071.

Mr. Hall: Schools of Law and Medicine, Wake Forest University, Worrell Professional Center, PO Box 7206, Reynolds Station, WinstonSalem, NC 27109.

Dr. Horwitz: Department of Medicine, Stanford University School of Medicine, 300 Pasteur Drive, Room S102, MC 5110, Stanford, CA 94305.

Mr. Hooven: Enable Medical Technologies, 7778 Bennington Drive, Cincinnati, OH 45241.

Mr. Jacobson: School of Public Health, University of Michigan, 109 Observatory Street, Ann Arbor, MI 48109.

Mr. Jost: School of Law, Washington and Lee University, 4008 Sydney Lewis Hall, Lexington, VA 24450.

Dr. Kotlikoff: Department of Economics, Boston University, 270 Bay State Road, Boston, MA 02215.

Dr. Levine: The Permanente Medical Group, 1950 Franklin Street, 20th Floor, Oakland, CA 94612.

Dr. Levy: Varian Medical Systems, 3100 Hansen Way, M/S E-220, Palo Alto, CA 94304.

Ms. Linscott: The Leapfrog Group, 1150 17th Street Northwest, Suite 600, Washington, DC 20036.
Dr. Luft: Palo Alto Medical Foundation Research Institute, 795 El Camino Real, Palo Alto, CA 94301.

Dr. Mashal: Alinea Pharmaceuticals, 1 Memorial Drive, Suite 1225, Cambridge, MA 02142.

Dr. McFadden: Department of Economics, University of California, Berkeley, 508-1 Evans Hall \#3880, Berkeley, CA 94720-3880.

Dr. Mechanic: Institute of Health, Health Care Policy and Aging Research, Rutgers University, 30 College Avenue, New Brunswick, NJ 08901.

Dr. Meltzer: Departments of Medicine and Economics and School of Public Policy, University of Chicago, 5841 South Maryland Avenue, MC 2007, Chicago, IL 60637.

Dr. Newhouse: Schools of Medicine, Public Health, Government, and Arts and Sciences, Harvard University, 180 Longwood Avenue, Boston, MA 02115.

Dr. Pietzsch: Department of Management Science and Engineering, Stanford University, Terman Engineering Center, 3rd Floor, 380 Panama Way, Stanford, CA 94305-4026.

Dr. Pizzo: School of Medicine, Stanford University, 300 Pasteur Drive, Room M-121, Stanford, CA 94305-5119.

Dr. Reischauer: The Urban Institute, 2100 M Street NW, Washington, DC 20037.

Ms. Rosenbaum: School of Public Health, George Washington University, $2021 \mathrm{~K}$ Street NW, Suite 800, Washington, DC 20006.

Dr. Sage: School of Law, University of Texas at Austin, 727 East Dean Keeton Street, Austin, TX 78705.

Mr. Schaeffer: University of Southern California, Lewis Hall 312, Los Angeles, CA 90089-0626.

Dr. Sheen: School of Public Health, Harvard University, 677 Huntington Avenue, Boston, MA 02115.

Dr. Silber: Department of Neurology, School of Medicine, University of California, San Francisco, 513 Parnassus Avenue, San Francisco, CA 94143.

Dr. Skinner: Dartmouth Institute for Health Policy \& Clinical Practice, Dartmouth School of Medicine, 6106 Rockefeller Hall Dartmouth College, Hanover, NH 03755-3514.

Dr. Shortell: School of Public Health, University of California, Berkeley, 50 University Hall, Berkeley, CA 94720.

Dr. Thier: Departments of Medicine and Health Policy, Harvard Medical School, 55 Fruit Street, Boston MA 02114.

Dr. Tunis: Center for Medical Technology Policy, 4712 Keswick Road, Baltimore, MD 21210.

Mr. Wulsin: Insure the Uninsured Project, 2444 Wilshire Boulevard, Suite 415, Santa Monica, CA 90403.

Dr. Yock: Department of Bioengineering, Stanford University, 318 Campus Drive, Room E100, Stanford, CA 94305-5428.

Mr. Bin Nun: Department of Health System Management, Ben Gurion University of the Negev, PO Box 653, Beer Sheva 84105, Israel.

Dr. Bryan: Department of Health Economics, University of Birmingham, Edgbaston, Birmingham B15 2TT, United Kingdom.

Dr. Luxenburg: Ministry of Health, Israel, 2 Ben Tabai Sreet, Jerusalem, Israel 93591.

Dr. van de Ven: Erasmus University, PO Box 1738, 3000 DR Rotterdam, the Netherlands. 